\title{
GMR
}

\section{Correlation between polymorphisms in the visfatin gene and its expression in the serum and coronary artery calcification}

\author{
L.W. Jin, S.B. Zheng, Z.H. Zhou, S.F. Pan and Y. Zheng \\ Urology Department, Wenxhou Medical University Second Affiliated Hospital, \\ Wenzhou, China \\ Corresponding author: L.W. Jin \\ E-mail: jlw918105@126.com
}

Genet. Mol. Res. 15 (2): gmr.15028217

Received December 7, 2015

Accepted February 11, 2016

Published July 15, 2016

DOI http://dx.doi.org/10.4238/gmr.15028217

\begin{abstract}
We investigated the association between serum visfatin levels and single nucleotide polymorphisms (SNPs; rs61330082, rs2058539) in the visfatin gene and coronary artery calcification (CAC) in patients from Wenzhou, China. CAC patients $(\mathrm{N}=206)$ were divided into two groups: mild CAC (MCAC) and moderate and severe CAC (MSCAC). Volunteers without CAC $(\mathrm{N}=70)$ were included in the control group. The serum visfatin level was analyzed by enzyme-linked immunosorbent assay. SNPs (rs61330082, rs2058539) in the visfatin gene were analyzed by polymerase chain reaction-restriction fragment length polymorphism. Clinical data, serum visfatin levels, and genotype and allele frequencies of rs61330082 and rs2058539 were compared among the three groups. MSCAC patients expressed significantly higher serum visfatin levels $(30.58 \pm 6.12 \mathrm{ng} / \mathrm{mL})$ than individuals in the MCAC $(29.03 \pm 1.87 \mathrm{ng} / \mathrm{mL})$ and control $(24.45 \pm 5.44 \mathrm{ng} /$ $\mathrm{mL})$ groups $(\mathrm{P}<0.05)$. The genotype distributions and frequencies of rs61330082 differed significantly among the groups $(\mathrm{P}<0.05)$, while those of rs2058539 did not. The serum visfatin level was positively correlated with the body mass index (BMI), high-density lipoprotein
\end{abstract}


cholesterol (HDL-C), and insulin resistance index (IRI), and negatively correlated with the triglyceride $(\mathrm{TG})$ levels $(\mathrm{P}<0.05)$ of patients. Serum visfatin is associated with the development of CAC. The T allele of the rs61330082 SNP in the visfatin gene had a cardioprotective effect on patients with CAC; the SNP at rs2058539 was not significantly associated with CAC. The BMI, HDL-C, IRI, and TG levels influenced the development of CAC.

Key words: Coronary artery calcification; Visfatin; Single nucleotide polymorphisms

\section{INTRODUCTION}

Coronary atherosclerosis is a pathological change associated with coronary heart disease (CHD). Coronary artery calcification (CAC) is a major diagnostic marker of CHD. The identification of CAC could be useful in the detection of coronary atherosclerosis and the identification of disease degree (Goldstein and Scalia, 2004). Multiple factors influence the induction and development of CHD. The adipokine visfatin, an adipocyte factor with the ability to reduce the blood sugar content (similar to insulin) (Tarride et al., 2009; Shaker et al., 2011) and to improve the synthesis and storage of adipocyte (Bulcão et al., 2006), was first identified by Fukuhara et al. (2005). Adipose tissues are sources of energy as well as the hormone leptin (Zhang et al., 1994; Bountouris et al., 2009). Previous studies (Fried et al., 1998; Blüher, 2013) have indicated that adipokines, which are signaling proteins secreted by the adipose tissue and visceral fat, perform versatile regulatory functions during the various stages of multiple diseases including obesity, diabetes, inflammation (Moschen et al., 2007), metabolic disorders (Dahl et al., 2007; Shaker et al., 2011), endothelial dysfunction (Dahl et al., 2007; Filippatos et al., 2010, 2013), atherosclerosis, hypertension, and ischemic reperfusion injury (Karaduman et al., 2006; Dahl et al., 2007; Tousoulis et al., 2008; Filippatos et al., 2013). However, the role of visfatin in these diseases may be pleiotropic.

The study of the correlation between visfatin and CAC remains largely ignored. Specifically, no previous study has attempted to elucidate the association between serum visfatin levels and the related single nucleotide polymorphisms (SNPs; rs61330082, rs2058539) and $\mathrm{CAC}$ in patients from Wenzhou, China. In this study, we investigated the association between serum visfatin levels and its SNPs at rs61330082 and rs2058539 and CAC in patients from the Wenzhou region, in order to analyze and identify the genetic variants at rs61330082 and rs2058539 in this population.

\section{MATERIAL AND METHODS}

\section{Patients and diagnostic criteria}

We recruited 206 CAC patients (127 males, 79 females) hospitalized at the Wenzhou Medical University Second Affiliated Hospital between January 1, 2008 and December 31, 2012 to this study. Seventy healthy volunteers (41 males, 29 females; average age 65.21 \pm 10.82 years) were included as controls. This study was approved by the medical Ethics Committee of the Wenzhou Medical University Second Affiliated Hospital. Informed consent 
was obtained from all patients and volunteers.

The patients were diagnosed with CAC by coronary angiography, and were divided into two groups, based on the severity of CAC: mild CAC (MCAC: 60 males, 39 females; average age $58.56 \pm 10.73$ years) and moderate and severe CAC (MSCAC: 67 males, 40 females; average age $69.30 \pm 11.49$ years). The patients were included if the degree of stenosis was $\geq 50 \%$ of the diameter of the main branch of the coronary artery. Patients with diabetes; those with acute or chronic infections 1 month prior to the angiography; patients who had undergone an operation or trauma at least 3 months prior to the angiography; patients with chronic connective tissue or valvular heart diseases; patients with cancer or tumors; and those with severe renal dysfunction were excluded from the study.

\section{Clinical data}

The gender (male/female), age, waist circumference (WC), and body mass index (BMI); fasting blood glucose (FBG), uric acid (UA), urea nitrogen (UN), creatinine (Cr), triglyceride (TG), total cholesterol (TC), high-density lipoprotein cholesterol (HDL-C), low-density lipoprotein cholesterol (LDL-C), high-sensitive C-reactive protein (hsC$\mathrm{RP}$ ), and urinary albumin (Alb) levels; and insulin resistance index (IRI) of all patients and volunteers were determined using standard tests, and reported as means \pm standard deviations (Table 1).

\begin{tabular}{|c|c|c|c|}
\hline Clinical data & Control group & MCAC group & MSCAC group \\
\hline Gender (M/F) & $41 / 29$ & $60 / 39$ & $67 / 40$ \\
\hline Age (years) & $65.21 \pm 10.82$ & $58.56 \pm 10.73$ & $69.30 \pm 11.49$ \\
\hline WC (cm) & $98.10 \pm 14.33$ & $106.82 \pm 14.67$ & $107.63 \pm 13.25$ \\
\hline BMI & $23.02 \pm 6.43$ & $26.95 \pm 6.70$ & $28.26 \pm 3.92$ \\
\hline FBG (mM) & $5.57 \pm 4.67$ & $5.85 \pm 6.91$ & $5.93 \pm 7.32$ \\
\hline UA $(\mathrm{mM})$ & $360.76 \pm 56.04$ & $363.77 \pm 101.35$ & $368.20 \pm 91.76$ \\
\hline $\mathrm{UN}(\mathrm{mM})$ & $5.40 \pm 2.13$ & $6.13 \pm 3.98$ & $6.22 \pm 3.04$ \\
\hline $\mathrm{Cr}(\mathrm{mg} / \mathrm{L})$ & $70.54 \pm 22.87$ & $73.01 \pm 28.03$ & $73.66 \pm 30.95$ \\
\hline TG (mM) & $1.60 \pm 0.38$ & $2.01 \pm 1.67^{*}$ & $2.26 \pm 1.54^{*}$ \\
\hline $\mathrm{TC}(\mathrm{mM})$ & $4.78 \pm 1.69$ & $4.90 \pm 1.54$ & $4.93 \pm 1.37$ \\
\hline HDL-C (mM) & $1.02 \pm 0.48$ & $1.09 \pm 0.56$ & $1.13 \pm 0.78$ \\
\hline LDL-C (mM) & $2.89 \pm 1.14$ & $2.33 \pm 0.76$ & $2.65 \pm 0.98$ \\
\hline hsC-RP (mg/L) & $5.82 \pm 8.69$ & $5.65 \pm 4.02$ & $5.70 \pm 7.73$ \\
\hline $\operatorname{Alb}(\mathrm{mg} / \mathrm{L})$ & $13.40 \pm 16.90$ & $18.04 \pm 26.37$ & $18.55 \pm 23.46$ \\
\hline IRI & $2.90 \pm 1.98$ & $4.12 \pm 1.96^{*}$ & $4.26 \pm 2.55^{*}$ \\
\hline \multicolumn{4}{|c|}{$\begin{array}{l}\text { MCAC = mild CAC; } \mathrm{MSCAC}=\text { moderate and severe } \mathrm{CAC} ; \mathrm{WC}=\text { waist circumference; } \mathrm{BMI}=\text { body mass index; } \\
\mathrm{FBG}=\text { fasting blood glucose; } \mathrm{UA}=\text { uric acid; } \mathrm{UN}=\text { urea } \mathrm{nitrogen} ; \mathrm{Cr}=\text { creatinine; } \mathrm{TG}=\text { triglyceride; } \mathrm{TC}=\text { total } \\
\text { cholesterol; } \mathrm{HDL}-\mathrm{C}=\text { high-density lipoprotein cholesterol; } \mathrm{LDL}-\mathrm{C}=\text { low-density lipoprotein cholesterol; hSC-RP } \\
=\text { high-sensitive } \mathrm{C} \text {-reactive protein; } \mathrm{Alb}=\text { urinary albumin, } \mathrm{IRI}=\text { insulin resistance index. }{ }^{*} \mathrm{P}<0.05 \text { compared to } \\
\text { the control group. }\end{array}$} \\
\hline
\end{tabular}

\section{Coronary angiography}

The right femoral arteries of all patients were examined using Judkin's method (Garrett et al., 1974). Each vessel expressed at least two postural projections. The results were judged, and agreed upon, by two chief physicians with more than 20 years of experience. 


\section{CAC diagnostic criteria}

Patients were categorized based on the degree of calcification in their coronary artery into four groups (Gulati et al., 2005): without calcification: without shadow; mild calcification: with slight and fuzzy shadow in the beating heart; moderate calcification: with a slightly clear shadow in the beating heart; and severe calcification: with clear shadow despite the beating of the heart.

All healthy volunteers also received a coronary angiography (employing the same method); the liver function, Doppler echocardiograph, and electrocardiogram, of all volunteers were normal; moreover, the volunteers did not display CAC or coronary atherosclerosis.

\section{Sample collection}

Venous blood samples were collected after a 12 -h fast from all patients and volunteers, in tubes (BD Biosciences, Franklin Lakes, NJ, USA). Ethylenediaminetetraacetic acid (EDTA; Solarbio Technology Co., Ltd., Beijing, China) was added to each blood sample.

\section{Detection of serum visfatin levels}

The blood samples $(3 \mathrm{~mL})$ were centrifuged at $3000 \mathrm{rpm}$ for $10 \mathrm{~min}$ and the supernatant was collected from each tube. Serum visfatin levels were detected using a standard enzyme-linked immunosorbent assay kit (TaKaRa Bio Inc., Dalian, China) according to the manufacturer instructions.

\section{Genomic DNA extraction and polymerase chain reaction-restriction fragment length polymorphism (PCR-RFLP)}

Genomic DNA was extracted from $2 \mathrm{~mL}$ blood using a standard DNA extraction kit (Thermo Fisher Scientific, St. Louis, MO, USA) according to the manufacturer protocol, and stored at $-80^{\circ} \mathrm{C}$.

The primers were designed by Invitrogen ${ }^{\mathrm{TM}}$ (Life Technologies, Carlsbad, CA, USA) (Table 2). The 50- $\mu \mathrm{L}$ PCR system (Table 3) was prepared using a standard PCR kit (Thermo Fisher Scientific) according to the manufacturer instructions, and the reaction conditions were set as summarized in Table 4 . The PCR products were digested with a restriction endonuclease (Table 5). The PCR products $(5 \mu \mathrm{L})$ were then separated on a $1.8 \%$ agarose gel with $1 \mu \mathrm{L}$ loading buffer. The restriction-digested products $(6 \mu \mathrm{L})$ with $M v a \mathrm{I}$ and $H p h \mathrm{I}$ were separated and analyzed on $2 \%$ agarose gel.

Table 2. Polymerase chain reaction-restriction fragment length polymorphism (PCR-RFLP) primers.

\begin{tabular}{|c|c|c|c|}
\hline PCR sites & Size (bp) & Primers & \\
\hline \multirow{2}{*}{ rs61330082 } & \multirow[t]{2}{*}{344} & Forward & 5'-CCGGTAAAACACAGGGAAGAT-3' \\
\hline & & Reverse & 5'-ATTCTATCTGGGGGCAGTGAT-3' \\
\hline \multirow[t]{2}{*}{ rs2058539 } & \multirow[t]{2}{*}{273} & Forward & 5'-TTAACTTTGGTATTCTTGCCACT-3' \\
\hline & & Reverse & 5'-CAAAAATCCCCCAATTTCTGT-3' \\
\hline \multirow[t]{2}{*}{$\beta$-actin } & \multirow[t]{2}{*}{75} & Forward & 5'-GCTCTGGCTCCTAGCACCAT-3' \\
\hline & & Reverse & 5'-GCCACCGATCCACACAGAGT-3' \\
\hline
\end{tabular}


Table 3. Fifty-microliter polymerase chain reaction (PCR) system.

\begin{tabular}{l|c}
\hline & Volume $(\mu \mathrm{L})$ \\
\hline DNA template & 10 \\
\hline Primers & $\mathrm{F}: 1$ \\
\hline & $\mathrm{R}: 1$ \\
\hline $\mathrm{dNTP}(1 \mathrm{X})$ & 4 \\
\hline TaqMan $(1 \mathrm{X})$ & 0.25 \\
\hline PCR buffer $(1 \mathrm{X})$ & 5 \\
\hline $\mathrm{H}_{2} \mathrm{O}$ & 28.75 \\
\hline Total & 50 \\
\hline
\end{tabular}

Table 4. Polymerase chain reaction (PCR) amplification conditions.

\begin{tabular}{l|c|c|c}
\hline Step & Temperature $\left({ }^{\circ} \mathrm{C}\right)$ & Time & Number of cycles \\
\hline Pre-denaturation & $95^{\circ} \mathrm{C}$ & $5 \mathrm{~min}$ & \multirow{2}{*}{35 cycles } \\
\hline Denaturation & $94^{\circ} \mathrm{C}$ & $30 \mathrm{~s}$ & \\
\hline Annealing & $55^{\circ} \mathrm{C}$ & $30 \mathrm{~s}$ & 1 cycle \\
\hline Extension & $72^{\circ} \mathrm{C}$ & $1 \mathrm{~min}$ & \\
\hline Terminal extension & $72^{\circ} \mathrm{C}$ & $5 \mathrm{~min}$ & \\
\hline Storage & $4{ }^{\circ} \mathrm{C}$ & $\rightarrow \infty$ & \\
\hline
\end{tabular}

Table 5. Restriction endonuclease reaction.

\begin{tabular}{|c|c|c|c|c|}
\hline & \multicolumn{2}{|l|}{ Volume $(\mu \mathrm{L})$} & \multicolumn{2}{|c|}{ Volume $(\mu \mathrm{L})$} \\
\hline SNP product & Rs61330082 & 10 & rs2058539 & 10 \\
\hline \multirow[t]{3}{*}{ Restriction endonuclease } & $M v a \mathrm{I}$ & 1.0 & $H p h \mathrm{I}$ & 0.5 \\
\hline & FastDigest Green Buffer (10X) & 2.0 & NEB Buffer (10X) & 2.0 \\
\hline & $\mathrm{ddH}_{2} \mathrm{O}$ & 17 & $\mathrm{ddH}_{2} \mathrm{O}$ & 7.5 \\
\hline Restriction temperature & \multicolumn{4}{|c|}{$37^{\circ} \mathrm{C}$} \\
\hline Restriction time & \multicolumn{2}{|l|}{$10 \mathrm{~min}$} & \multicolumn{2}{|c|}{$20 \mathrm{~min}$} \\
\hline Total & & 30 & & 20 \\
\hline
\end{tabular}

NEB, New England Biolabs (Ipswich, MA, USA); SNP, single nucleotide polymorphism.

\section{Statistical analysis}

All data were analyzed using SPSS v.13.0 (SPSS Inc., Chicago, IL, USA). All data are reported as means \pm standard deviation. The differences in clinical data and serum visfatin levels between groups were determined by an independent-sample $t$-test. One-way analysis of variance was used to compare data among the three groups. The chi-squared test was used to analyze the enumerated data. The correlation between serum visfatin levels and clinical data was determined by multiple-linear regression analysis. The conformance of the genotype frequencies to the Hardy-Weinberg equilibrium was also analyzed. Differences with P values $<0.05$ were considered to be statistically significant.

\section{RESULTS}

\section{Comparison of clinical data}

The clinical data of subjects in the MCAC and MSCAC groups were compared to those of individuals in the control group; we observed no significant differences in the WC, BMI, FBG, UA, UN, Cr, TC, HDL-C, LDL-C, hsC-RP, and Alb levels. However, the TG (P< $0.05)$ and IRI $(\mathrm{P}<0.05)$ levels were observed to differ significantly (Table 1$)$. 


\section{Comparing the serum visfatin levels}

The serum visfatin concentrations in the MCAC and MSCAC groups were 29.03 \pm 1.87 and $30.58 \pm 6.12 \mathrm{ng} / \mathrm{mL}$, respectively, which were significantly higher than those observed in the control group $(24.45 \pm 5.44 \mathrm{ng} / \mathrm{mL} ; \mathrm{P}<0.05)$. However, we observed no significant difference between MCAC and MSCAC groups.

\section{Correlation between visfatin levels and clinical data}

The serum visfatin level was significantly positively correlated with the BMI, HDL-C, and IRI levels $(\mathrm{P}<0.05)$, and significantly negatively correlated to the TG level $(\mathrm{P}<0.05)$. We observed no significant correlation between the serum visfatin level and other clinical data (Table 6).

\begin{tabular}{|c|c|c|}
\hline Clinical data & Correlation coefficient (r) & $\mathrm{P}$ \\
\hline Gender (M/F) & 0.109 & 0.158 \\
\hline Age (years) & 0.138 & 0.083 \\
\hline $\mathrm{WC}(\mathrm{cm})$ & 0.182 & 0.114 \\
\hline BMI & 0.296 & $0.020^{*}$ \\
\hline FBG (mM) & 0.077 & 0.605 \\
\hline $\mathrm{UA}(\mathrm{mM})$ & -0.186 & 0.226 \\
\hline $\mathrm{UN}(\mathrm{mM})$ & -0.224 & 0.361 \\
\hline $\mathrm{Cr}(\mathrm{mg} / \mathrm{L})$ & 0.037 & 0.798 \\
\hline $\mathrm{TG}(\mathrm{mM})$ & -0.304 & $0.031 *$ \\
\hline $\mathrm{TC}(\mathrm{mM})$ & 0.265 & 0.194 \\
\hline $\mathrm{HDL}-\mathrm{C}(\mathrm{mM})$ & 0.217 & $0.040^{*}$ \\
\hline LDL-C (mM) & 0.196 & 0.156 \\
\hline hsC-RP (mg/L) & 0.201 & 0.179 \\
\hline $\mathrm{Alb}(\mathrm{mg} / \mathrm{L})$ & 0.184 & 0.190 \\
\hline IRI & 0.360 & $0.011 *$ \\
\hline
\end{tabular}

WC, waist circumference; BMI, body mass index; FBG, fasting blood glucose; UA, uric acid; UN, urea nitrogen; $\mathrm{Cr}$, creatinine; TG, triglyceride; TC, total cholesterol; HDL-C, high-density lipoprotein cholesterol; LDL-C, lowdensity lipoprotein cholesterol; hsC-RP, high-sensitive C-reactive protein; Alb, urinary albumin, IRI, insulin resistance index. $* \mathrm{P}<0.05$ compared to the control group.

\section{PCR-RFLP}

The PCR products were analyzed on $1.8 \%$ agarose gel; the visfatin gene fragments rs61330082 and rs2058539 were 344 and $273 \mathrm{bp}$ in length, respectively.

Restriction digestion of the PCR products rs61330082 and rs2058539 with MvaI and $H p h$ I yielded 3 (344, 233, and $111 \mathrm{bp})$ and 2 (122 and $151 \mathrm{bp}$ ) bands on 2\% agarose gel, respectively.

\section{Comparison of the genotype and allele frequencies}

The MSCAC and MCAC groups displayed significant differences in the genotype $\left(\chi^{2}=27.985\right)$ and allele $\left(\chi^{2}=23.101\right)$ frequencies of rs61330082 $(\mathrm{P}<0.05)$; however, the genotype and allele frequencies of rs2058539 did not differ significantly among the groups (Tables 7 and 8). A higher percentage of patients in the MSCAC group expressed the $\mathrm{C}$ allele (while the percentage of expression of the $\mathrm{T}$ allele was lower), compared to the individuals in 
the control and MCAC groups. On the other hand, the expression of the $\mathrm{C}$ allele was higher in patients in the MCAC group, compared to the A allele.

Table 7. Genotype frequencies of the rs61330082 and rs2058539 single nucleotide polymorphisms in the visfatin gene $[\mathrm{N}(\%)]$.

\begin{tabular}{l|c|c|c|c|c|c}
\hline \multirow{2}{*}{ Group } & \multirow{2}{*}{$\mathrm{N}$} & \multicolumn{3}{|c|}{ rs61330082 (C/T) } & \multicolumn{2}{c}{ rs2058539(A/C) } \\
\cline { 3 - 7 } & & CC & TT & CT & AA & $32(45.7)$ \\
\hline Control & 70 & $24(34.3)$ & $31(44.3)$ & $15(21.4)$ & $38(54.3)$ & $61(61.6)$ \\
\hline MCAC & 99 & $26(26.3)$ & $36(36.4)$ & $37(37.3)$ & $38(38.4)$ & $52(48.6)$ \\
\hline MSCAC & 107 & $58(54.2)$ & $28(26.2)$ & $21(19.6)$ & $55(51.4)$ & \\
\hline
\end{tabular}

MCAC, mild coronary artery calcification (CAC); MSCAC, moderate and severe CAC.

Table 8. Allele frequencies of the SNPs rs61330082 and rs2058539 in the visfatin gene [N (\%)].

\begin{tabular}{l|c|c|c|c|c}
\hline \multirow{2}{*}{ Groups } & \multirow{2}{*}{$\mathrm{N}$} & \multicolumn{2}{|c|}{ rs61330082(C/T) } & \multicolumn{2}{c}{ rs2058539(A/C) } \\
\cline { 3 - 6 } & & $\mathrm{C}$ & $\mathrm{T}$ & $\mathrm{A}$ & $\mathrm{C}$ \\
\hline Control & 70 & $63(45.0)$ & $77(55.0)$ & $76(54.3)$ & $64(45.7)$ \\
\hline MCAC & 99 & $89(44.9)$ & $109(55.1)$ & $76(38.4)$ & $122(61.6)$ \\
\hline MSCAC & 107 & $137(64.0)$ & $77(36.0)$ & $110(51.4)$ & $104(48.6)$ \\
\hline
\end{tabular}

SNP, single nucleotide polymorphism; MCAC, mild coronary artery calcification (CAC); MSCAC, moderate and severe CAC.

\section{Conformance with the Hardy-Weinberg equilibrium}

The genotype frequencies in the 206 patients and 70 volunteers were in conformance with the Hardy-Weinberg equilibrium, indicating the representativeness of these samples.

\section{DISCUSSION}

Visfatin is a cytokine that modulates nicotinamide phosphoribosyltransferase (NAMPT) activity in visceral adipose tissue and is secreted by lymphocytes activated at the bone marrow stromal cells. The 37.4-bp long visfatin gene, located between q22.1 and q31.33 on chromosome 7, is composed of 10 introns and 11 exons (de Carvalho et al., 2006). Chang et al. (2010) reported that visfatin promotes angiogenesis through the NF- $\kappa B$ and PI3K pathways, while Lu et al. (2009) showed that visfatin is an independent risk factor of coronary disease by demonstrating that patients with acute or chronic coronary disease (diagnosed by coronary angiography) showed higher levels of visfatin than individuals in the control group. Meanwhile, Garten et al. (2010) discovered a positive correlation between visfatin and LDL-C levels, and a negative correlation between visfatin and TG. However, Costford et al. (2010) reported a positive correlation between FBG and TG and visfatin, and a negative correlation between LDL-C and visfatin in obese patients. The TT genotype of the -4689 G/T SNP in the promoter region of the visfatin gene has been reported to influence the blood lipid levels, obesity, and insulin resistance (Berndt et al., 2005), while the GG genotype at this polymorphic site was only correlated with the fasting insulin levels.

Several previous studies have attempted to identify the correlation between serum visfatin levels and CHD; however, there are relatively fewer studies analyzing SNPs in the visfatin gene, specifically, the correlation between visfatin gene polymorphisms and CAC. 
Several experts are currently investigating the use of CAC to evaluate the risk of CHD, especially because of the poor prognosis of CHD patients with CAC. The degree of CAC is also associated with arterial stenosis, in addition to CHD. In this study, we identified a positive correlation between the serum visfatin levels and the extent of CAC; that is, the serum visfatin levels increased with CAC development, as reported by Kadoglou et al. (2011).

Pagano et al. (2006) reported a significant increase in the visfatin mRNA levels in the visceral adipose tissue of patients with obesity, in correlation with the BMI and distribution of adipose tissue (Berndt et al., 2005; Kamińska et al., 2010; Unlütürk et al., 2010). We observed a positive correlation between the serum visfatin levels and increased BMI, in addition to the association between these levels and CAC degree; that is, the BMI was an independent risk factor for CHD. This indicated that obesity is a basic risk factor for CHD, CAC, and diabetes.

Previous studies on diabetes (Kang et al., 2010) and CHD (Choi et al., 2008) have reported a positive correlation between the serum visfatin levels and insulin resistance; moreover, Chang et al. (2010) discovered a positive correlation between the visfatin mRNA expression in visceral adipose tissues and insulin resistance. The results of our study are in accordance with these results; that is, the IRI was positively correlated with the serum visfatin levels in patients with $\mathrm{CAC}$, indicating the important role played by visfatin in the insulin-resistance mechanism. Additionally, previous studies have reported a positive correlation between the serum and mRNA levels of visfatin and abnormal TG and HDL-C levels, indicative of patients with obesity. However, in this study, we discovered that the TG levels were negatively correlated to the visfatin expression (although HDL-C was positively correlated with visfatin). We attribute this difference to the ethnicity of the subjects and the complex functions of visfatin, among others.

The complications associated with CHD have led to an increasing number of studies on the correlation between the pathogenesis of CHD and SNPs in genes such as Apo-I and $A C E I$ (Raggi et al., 2003). In this study, we focused on the rs61330082 and rs2058539 polymorphisms in the visfatin gene of patients with CAC from the Wenzhou region of China. Patients with CAC showed increased serum visfatin levels, indicating damage to the vascular endothelial function and the severity of CAC. The results indicated a correlation between the $\mathrm{T}$ allele of the rs61330082 SNP and CAC; this hinted at the cardioprotective effect of the $\mathrm{T}$ allele. On the other hand, we observed no direct correlation between the rs2058539 SNP and CAC.

Coronary angiography is the most common tool used to diagnose CHD; however, this method has several limitations, including a prohibitive cost and a long hospital stay. Moreover, several patients have been known to reject the option of a coronary angiography because of the risks involved. In this study, we propose the diagnosis of patients with CAC or CHD using a simple-screening method for the serum and genotype distribution of visfatin; in addition to predicting the severity of arteriosclerosis development, this method can be used to develop novel ethnically targeted therapeutic drugs, as well as to assist in the early detection and prevention of CHD.

This study has certain limitations: only two SNPs in the visfatin gene were analyzed, of which, we only confirmed the association of one SNP (rs61330082) with CAC; moreover, the small sample size and unvaried ethnicity of the study population could influence the representativeness of the results. Therefore, further comprehensive investigations must be conducted into the correlation between SNPs in the visfatin gene and CHD or CAC in the future, with a larger sample size. 


\section{Conflict of interest}

The authors declare no conflict of interest.

\section{ACKNOWLEDGMENTS}

Research supported by a grant provided by the Wenzhou Municipal Science and Technology Bureau (Program \#Y20140057).

\section{REFERENCES}

Berndt J, Klöting N, Kralisch S, Kovacs P, et al. (2005). Plasma visfatin concentrations and fat depot-specific mRNA expression in humans. Diabetes 54: 2911-2916. http://dx.doi.org/10.2337/diabetes.54.10.2911

Blüher M (2013). Adipose tissue dysfunction contributes to obesity related metabolic diseases. Best Pract. Res. Clin. Endocrinol. Metab. 27: 163-177. http://dx.doi.org/10.1016/j.beem.2013.02.005

Bountouris I, Paraskevas KI, Koutouzis M, Tzavara V, et al. (2009). Serum leptin levels in patients undergoing carotid endarterectomy: a pilot study. Angiology 60: 698-704. http://dx.doi.org/10.1177/0003319709350133

Bulcão C, Ferreira SR, Giuffrida FM and Ribeiro-Filho FF (2006). The new adipose tissue and adipocytokines. Curr. Diabetes Rev. 2: 19-28. http://dx.doi.org/10.2174/157339906775473617

Chang YC, Chang TJ, Lee WJ and Chuang LM (2010). The relationship of visfatin/pre-B-cell colony-enhancing factor/ nicotinamide phosphoribosyltransferase in adipose tissue with inflammation, insulin resistance, and plasma lipids. Metabolism 59: 93-99. http://dx.doi.org/10.1016/j.metabol.2009.07.011

Choi KM, Lee JS, Kim EJ, Baik SH, et al. (2008). Implication of lipocalin-2 and visfatin levels in patients with coronary heart disease. Eur. J. Endocrinol. 158: 203-207. http://dx.doi.org/10.1530/EJE-07-0633

Costford SR, Bajpeyi S, Pasarica M, Albarado DC, et al. (2010). Skeletal muscle NAMPT is induced by exercise in humans. Am. J. Physiol. Endocrinol. Metab. 298: E117-E126. http://dx.doi.org/10.1152/ajpendo.00318.2009

Dahl TB, Yndestad A, Skjelland M, Øie E, et al. (2007). Increased expression of visfatin in macrophages of human unstable carotid and coronary atherosclerosis: possible role in inflammation and plaque destabilization. Circulation 115: 972-980. http://dx.doi.org/10.1161/CIRCULATIONAHA.106.665893

de Carvalho MH, Colaço AL and Fortes ZB (2006). Cytokines, endothelial dysfunction, and insulin resistance. Arq. Bras. Endocrinol. Metabol. 50: 304-312.

Filippatos TD, Randeva HS, Derdemezis CS, Elisaf MS, et al. (2010). Visfatin/PBEF and atherosclerosis-related diseases. Curr. Vasc. Pharmacol. 8: 12-28. http://dx.doi.org/10.2174/157016110790226679

Filippatos TD, Tsimihodimos V, Derdemezis CS, Gazi IF, et al. (2013). Increased plasma visfatin concentration is a marker of an atherogenic metabolic profile. Nutr. Metab. Cardiovasc. Dis. 23: 330-336. http://dx.doi.org/10.1016/j. numecd.2011.07.002

Fried SK, Bunkin DA and Greenberg AS (1998). Omental and subcutaneous adipose tissues of obese subjects release interleukin-6: depot difference and regulation by glucocorticoid. J. Clin. Endocrinol. Metab. 83: 847-850.

Fukuhara A, Matsuda M, Nishizawa M, Segawa K, et al. (2005). Visfatin: a protein secreted by visceral fat that mimics the effects of insulin. Science 307: 426-430. http://dx.doi.org/10.1126/science.1097243

Garrett J, Knight E, Fawzy EM, Pridie RB, et al. (1974). Proceedings: Coronary angiography using Judkins method. Br. Heart J. 36: 399.

Garten A, Petzold S, Barnikol-Oettler A, Körner A, et al. (2010). Nicotinamide phosphoribosyltransferase (NAMPT/ PBEF/visfatin) is constitutively released from human hepatocytes. Biochem. Biophys. Res. Commun. 391: 376-381. http://dx.doi.org/10.1016/j.bbrc.2009.11.066

Goldstein BJ and Scalia R (2004). Adiponectin: A novel adipokine linking adipocytes and vascular function. J. Clin. Endocrinol. Metab. 89: 2563-2568. http://dx.doi.org/10.1210/jc.2004-0518

Gulati GS, Seth S, Kurian S, Jagia P, et al. (2005). Non-invasive diagnosis of coronary artery disease with 16-slice computed tomography. Natl. Med. J. India 18: 236-241.

Kadoglou NP, Gkontopoulos A, Kapelouzou A, Fotiadis G, et al. (2011). Serum levels of vaspin and visfatin in patients with coronary artery disease-Kozani study. Clin. Chim. Acta 412: 48-52. http://dx.doi.org/10.1016/j.cca.2010.09.012

Kamińska A, Kopczyńska E, Bronisz A, Zmudzińska M, et al. (2010). An evaluation of visfatin levels in obese subjects. Endokrynol. Pol. 61: 169-173. 
Kang YS, Song HK, Lee MH, Ko GJ, et al. (2010). Plasma concentration of visfatin is a new surrogate marker of systemic inflammation in type 2 diabetic patients. Diabetes Res. Clin. Pract. 89: 141-149. http://dx.doi.org/10.1016/j. diabres.2010.03.020

Karaduman M, Oktenli C, Musabak U, Sengul A, et al. (2006). Leptin, soluble interleukin-6 receptor, C-reactive protein and soluble vascular cell adhesion molecule-1 levels in human coronary atherosclerotic plaque. Clin. Exp. Immunol. 143: 452-457. http://dx.doi.org/10.1111/j.1365-2249.2006.03025.x

Lu LF, Yang SS, Wang CP, Hung WC, et al. (2009). Elevated visfatin/pre-B-cell colony-enhancing factor plasma concentration in ischemic stroke. J. Stroke Cerebrovasc. Dis. 18: 354-359. http://dx.doi.org/10.1016/j. jstrokecerebrovasdis.2009.01.003

Moschen AR, Kaser A, Enrich B, Mosheimer B, et al. (2007). Visfatin, an adipocytokine with proinflammatory and immunomodulating properties. J. Immunol. 178: 1748-1758. http://dx.doi.org/10.4049/jimmunol.178.3.1748

Pagano C, Pilon C, Olivieri M, Mason P, et al. (2006). Reduced plasma visfatin/pre-B cell colony-enhancing factor in obesity is not related to insulin resistance in humans. J. Clin. Endocrinol. Metab. 91: 3165-3170. http://dx.doi. org/10.1210/jc.2006-0361

Raggi P, Cooil B, Shaw LJ, Aboulhson J, et al. (2003). Progression of coronary calcium on serial electron beam tomographic scanning is greater in patients with future myocardial infarction. Am. J. Cardiol. 92: 827-829. http:// dx.doi.org/10.1016/S0002-9149(03)00892-0

Shaker O, El-Shehaby A, Zakaria A, Mostafa N, et al. (2011). Plasma visfatin and retinol binding protein-4 levels in patients with type 2 diabetes mellitus and their relationship to adiposity and fatty liver. Clin. Biochem. 44: 14571463. http://dx.doi.org/10.1016/j.clinbiochem.2011.08.1148

Tarride JE, Lim M, DesMeules M, Luo W, et al. (2009). A review of the cost of cardiovascular disease. Can. J. Cardiol. 25: e195-e202. http://dx.doi.org/10.1016/S0828-282X(09)70098-4

Tousoulis D, Charakida M and Stefanadis C (2008). Endothelial function and inflammation in coronary artery disease. Postgrad. Med. J. 84: 368-371. http://dx.doi.org/10.1136/hrt.2005.066936

Unlütürk U, Harmanci A, Yildiz BO and Bayraktar M (2010). Dynamics of Nampt/visfatin and high molecular weight adiponectin in response to oral glucose load in obese and lean women. Clin. Endocrinol. 72: 469-474. http://dx.doi. org/10.1111/j.1365-2265.2009.03674.x

Zhang Y, Proenca R, Maffei M, Barone M, et al. (1994). Positional cloning of the mouse obese gene and its human homologue. Nature 372: 425-432. http://dx.doi.org/10.1038/372425a0 